\title{
Experiences of Adopting Blended Pedagogies in Health Assessment Course in Post RN Baccalaureate Program of Nursing in Karachi, Pakistan
}

\author{
Shanaz Hussein Cassum ${ }^{1}$, Saleema Allana ${ }^{2}$, Jacqueline Dias ${ }^{1}$ \\ ${ }^{1}$ The Aga Khan University School of Nursing and Midwifery, Pakistan \\ Correspondence: Shanaz Hussein Cassum, The Aga Khan University School of Nursing and Midwifery, Pakistan
}

Received: June 29, 2015 Accepted: July 8, 2015 Online Published: October 26, 2015

doi:10.11114/jets.v4i1.1168 URL: http://dx.doi.org/10.11114/jets.v4i1.1168

\begin{abstract}
Purpose: There is little known about whether faculty and students in a resource constricted context experience a change in learning due to the adoption of blended learning (BL) pedagogies in a lab based course. The study aimed to understand the experiences of faculty and students' related to the adoption of BL pedagogies in health assessment course.
\end{abstract}

Design: An action research design was used in this study to integrate planning, action and research in the setting where the change is required. The study sample consisted of year 1 Post RN BScN students enrolled at the Aga Khan University School of Nursing and Midwifery, and the faculty assigned to teach in Health Assessment course. Of the 83 Post RN BScN students and the 6 nursing faculty invited, 53 students and 6 teachers $(n=59)$ consented to participate in the study. Data was collected using focus group discussions.

Results: Findings revealed five major categories; Students' readiness, motivation and self- directedness; Teacher competence, commitment, and comfort; Use of blended strategies; Resources; and Contextual factors \& challenges.

Conclusion: This study was the first of its kind in Pakistan. The findings of the study indicate towards the ways that can improve the use of BL in a resource constrained context.

Keywords: blended learning, baccalaureate program, faculty and student experiences

\section{Introduction}

Blended learning $(\mathrm{BL})$ is a hybrid of face to face $(\mathrm{F} 2 \mathrm{~F})$ learning with e-learning, whereby the interaction between student and teacher is not confined by the classroom space, time and distance factors. It is known that students show more readiness to take learning responsibility if they actively engage in their learning (Cassum, 2011). Use of blended pedagogies is identified as a catalyst to engage students and promote self -directed learning. While some theory based courses lend themselves well to blended learning, developing a clinical skills based course using blended approaches, presents additional challenge to faculty in a resource constricted context. Little is known about how in a resource constrained context, a traditional faculty in an e learning world, adopts blended learning approaches to maximize student learning. The Faculty in the baccalaureate program wanted to explore how best to adopt blended learning approaches in a clinical skill based nursing course as there is limited experience and exposure to such techniques in low resource contexts (such as Pakistan). The study aimed to understand the experiences of faculty and students related to the adoption of a blended format course within a resource constrained context. The research question studied was; "What are the faculty and students' experiences while adopting the blended learning pedagogies in health Assessment course"?

\section{Literature Review}

Blended learning (BL) has gained enormous importance in higher education, over the past few years. The shift from F2F to $\mathrm{BL}$ is driven by several factors including increased access, higher efficiency, time effectiveness, and lesser monetary investment (Skiba, Connors, \& Jeffries, 2008). Several undergraduate nursing programs have adopted BL approach either fully or partially (Gagne, Bisanar, Makowski, \& Neumann, 2012). Integration of information technology (IT) in undergraduate nursing curricula not only brings upon the above mentioned advantages, but it also prepares nurses to take up the challenge of working in technologically advanced settings (Gagne et al., 2012). Additionally, with the increasing emphasis on evidence based practice, it is essential that nurses must be well equipped with the IT skills to be able to access the current evidence and to utilize it in their practice (Fetter, 2008). Several studies have considered the development, 
planning, and execution of blended learning programs in nursing education. Connors et al. (2002) reported immense satisfaction of faculty and students with the use of BL strategies. McDowell and Ma (2007) evaluated self-reported competence of undergraduate nursing students in using informatics, on admission and on graduation, within the context of completing a BL integrated program. They reported a significant improvement in students' internet surfing, presentation preparation, database searching, and statistical programs usage skills. Hsu (2011) reported that when they applied BL to an ethics course in an UG nursing program in Taiwan, the result was quite positive, with $57.8 \%$ of the students, rating the course as extremely or very helpful.

Contrary to the benefits, some studies identified barriers to successful integration of BL in baccalaureate nursing education programs. Deltsidou, Gesouli-Voltyraki, Mastrogiannis, and Noula (2010) conducted a study on integration of BL in one of the nursing programs in Greece, where they identified lack of word processing and internet skills, as well as decreased accessibility to internet connections as the major obstacles. Fetter (2009) reported some barriers such as IT skills and infrastructure deficits, lack of support by administration, ambiguity in expectations from the students, and lack of any IT integration standards by the national nursing accreditation bodies.

Nursing education literature reports the utilization of mobile learning, virtual reality and podcasting in nursing education. Mobile learning strategy is extensively cited in nursing education literature, with use of handheld devices such as personal digital assistants (PDAs) both within the classroom and clinical settings. Several studies indicated that PDAs in the clinical setting allowed students to save time and access real time accurate information, building learning currency (Farrell \& Rose, 2008; Garrett \& Jackson, 2006; Koeniger-Donohue, 2008). Virtual reality (VR), a relatively new blended technology, can enable students to practice clinical skills via electronic simulation until competency is demonstrated. VR has been utilized in various nursing courses including medical surgical nursing, mental health nursing and emergency nursing (Aebersold, Tschannen, \& Bathish, 2012; Honey, Diener, Connor, Veltman, \& Bodily, 2009; Kidd, Morgan, \& Savery, 2012; Lewis, 2009).

Podcasting strategy is also widely used, as it provides interactive teaching material such as lectures and power point presentations to the students. Studies have yielded positive student feedback in understanding content and increasing student engagement, with the use of podcasts (Pearce and Scutter, 2010; Schlairet's, 2010; Strickland, Gray, \& Hill, 2012).

In light of the given literature, it is evident that different blended strategies have been used in nursing education. However, as the studies reviewed are from the West, it is anticipated that the integration of blended learning in nursing education programs in Pakistani context, may result in different experiences and outcomes, considering the differences in student and faculty characteristics, organizational factors, access to limited resources, and their competence in dealing with technology. Moreover, considering the skill based nature of health assessment course, adopting BL strategies may be challenging to both students and faculty, thus articulating their experiences will enrich course of action on blended learning adoption.

\section{Methodology}

An action research (AR) design was used for the study, which is a problem centered and action oriented process (Holloway \& Wheeler, 2002; McNiff \& Whitehead, 2000). Faculty who participated in a faculty development project, designed the blended health Assessment course, and became the direct participants of this research. However, data was also collected from the students enrolled in the course, to understand their experiences, although they were not the direct participants of the study. The nursing faculty who facilitated students' learning, as well as the enrolled students were invited to be the study participants. 6 faculty, 4 of which were also researchers and 53 out of 83 students consented to take part in the study.

\section{Ethical Consideration}

Permission to conduct the study was obtained from the University Ethics Review Committee. Course participants including students and teachers were invited to participate in the study via a letter of invitation, and return of consent form implied their willingness to participate in the study. The participants had the right to refuse and withdraw from the study without giving any explanation, at any time. Identification of the research participants was kept confidential and did not affect the course performance in any way. The findings are reported in an aggregated manner as per the themes so the individual participants' identity is not known. Measures were undertaken to assure that the faculty who facilitated those groups did not conduct those student focus group interview as a researcher, in order to avoid any conflict of interest and to provide confidentiality to the students.

\section{Data collection and Analysis}

Data was collected through a) demographic questionnaire to survey the participants' profile and comfort with IT skills and b) focus group discussions of faculty and students to identify their experiences towards use of BL pedagogies. The 
demographic profile was analyzed quantitatively using SPSS version 19 and descriptive analysis like mean and standard deviation was employed to explore participants' profile and their IT capabilities. 4 FGDs were conducted, (3 students' focus groups \& 1 faculty focus group). Each FGD lasted about $1-1.5$ hours and had 6 - 20 participants. A questioning guide was developed for use in FGD to explore the participants' experiences and challenges in adopting BL pedagogies. The FGDs were recorded and transcribed by a hired transcriptionist. The transcripts were reviewed by the researchers to make sense of the data and analyzed using manual content analysis. Data saturation was achieved when no additional codes or categories were identified. Content analysis revealed over 25 sub categories which were then grouped into 5 categories. These categories described the faculty and students experiences towards adopting blended learning and address the research question.

\section{Findings}

\subsection{Demographic Profile}

The participation response rate was $68.75 \%$. All 6 nursing faculty were female with a range of $6-27$ years of teaching experience. Of the 53 students, 46 were females and 7 were males. Both full time and part time students were present in the first year of the Post RN BScN program. They had a range of $1-10$ years of experience as a registered nurse. Interestingly, most participants had no experience of blended learning, and many did not possess personal lap tops. As part of the course enrollment, all were provided a handheld e reader device (NOOK) to facilitate them to access the course site and promote flexible learning when not on campus. Many participants had experience of using computers or their smart phone for chatting and playing games for leisure and checking emails but not for learning for academic courses. Most participants' voiced a fair level of comfort in use of computers (Excellent 3.3\%, Good = 46.7\%, Fair = $38.3 \%$, Poor $11.7 \%$ ).

\subsection{Faculty and Students' Experiences of Adopting Blended Learning}

\subsubsection{Category 1: Student Readiness, Motivation and Self- directedness}

For most students, BL course was a new, interesting and challenging experience that enriched their learning. Some stated that it was difficult, problematic, and demanded more from them in terms of responsibility, discipline and time management. Students shared that they were excited to try out this blended formatted course, as it offered them flexibility with time and space. However, they need time and guidance in becoming more confident with self- directed learning. A student stated;

Blended approach in health assessment is a good experience...It's a new experience for all of us too. Sometimes it becomes painful because it's a new change and you know people have difficulty to accept the new change.... in blended learning we have time to study on our convenient time, at home, with our families... I think we need some time but we will adjust soon, most of us have adjusted but, there are things we need to accept and that is the reality. (FG1).

Teachers also felt that previously teacher used to come prepared for giving lecture but students did not do much pre readings. Now with blended format, students are taking more responsibility, and trying to move from a traditional teacher centered class to a student centered class. One faculty stated:

This is a positive start from the students as they do not expect from teacher now to come and regurgitate the information in a lecture, they are getting into the self-directed mode. Face to face sessions have now become more meaningful and classrooms are more student centered and less teacher centered... students have kind of equal participation in terms of sharing knowledge, and teaching is not only teacher's responsibility... (FG4)

\subsubsection{Category 2: Teacher Competence, Commitment, and Comfort}

Teachers' comfort, commitment and competence related to use of blended tools influenced the transformation of the course into a blended format. Teachers shared that they were excited to experiment this new project as their interest and capacity to transform the course into a blended format was kindled during the BL training workshop. However, all faculty stated that their time commitment increased from conducting a 2 hours/ week class to 6 - 8 hours commitment, as it requires development of module prior to the week and then facilitation of students during the given week. A faculty explained;

In face to face we had 2 hour session and the topic would close but in blended format, a module runs for 1 - 2 weeks, and during the entire week, students dialogue in discussion forums and faculty is expected to facilitate \& contribute to their learning. This is more time consuming as compared to face to face where we would spend 2-4 hours and the topic will close. (FG4)

As this was the first time around, the efforts in planning, executing, and uploading a module demanded more time from faculty as compared to delivering a lecture in a traditionally formatted course. A faculty workload in regards to preparing 
a module included writing up of entire module script, learning objectives, activities and creating assessment activities. Faculty was required to search online resources, and create student learning opportunities and assessments tests. The word template was then packaged into an EXE file for being uploaded to the university course site for student to access. A faculty sharing her frustrations of this process stated;

We have to go through websites to identify which image is appropriate to our module whereas I have a book in front me but I can't upload it or put it on the course site. Although there are more than 5000 pictures on internet sites but I have to review and identify which is best and from an open source... that was time consuming for the faculty in terms of finding the resources and images (FG4)

Although time was a concern, faculty comfort and competence was enhanced by mentorship and support from each other, as they all worked in a team and supported each other to learn the variety of blended pedagogies used in the course.

\subsubsection{Category 3: Blended Strategies}

A number of strategies were used to provide a mix of F2F and virtual learning in the course. These included self-study modules, online forum, self- tests, and use of virtual labs. A student admiring the use of diverse strategies in the course said;

blended learning is quite challenging... we have to study by ourselves, initially it was very difficult... I am a kind of visual learner so I understand better when someone is standing in front and teaching ... In fact, if text is written it is difficult for me to read and understand, but in Health Assessment course, it covers all aspects like reading, discussions, quizzes, as well as vodcast in which faculty was visible to us so it was helpful (FG3).

Students and faculty both felt that the amount \& quality of interaction between faculty to student, and student to student increased due to blended mode of the course. Students liked the independent self study modules, as they could study them in their own time and home and review the given resources and complete tasks and activities multiple times. A student said;

Good thing about the modules is that the teacher's power point presentations are focused, simple and self-explanatory, although there are some new terms which we don't know, so when we are reading at home in our own time, we can't understand but if need clarification, I can ask in querry corner or in discussion forum and the teacher or any peer answers (FG1)

Virtual lab (VL) was another creative strategy where students practiced independently after watching faculty vodcasts (video clips). Students were expected to prepare own vodcasts when practicing an assessment skill on a peer and then faculty and peers gave feedback on their assessment skill. A faculty commenting on the usefulness of the vodcast said;

I was doubtful about virtual lab usefulness since the beginning and I was not sure whether we will get the essence of teaching assessment skills to students or not but when students prepared vodcasts, they were so good that we are able to gauge effectively what a student was demonstrating, even intricacies of skin abnormalities and lesions were shown, and we could see easily and give them feedback. (FG4).

\subsubsection{Category 4: Resources}

A hand held e reader (NOOK tablet) was loaned to students and faculty for the entire semester to access the course site anytime. Participants appreciated the loaned device as many did not have personal laptops, and the desktops in learning resource center (LRC) were few. However, students shared some concerns as well:

Nook is helpful, but when it hangs, then everything finishes. Because of nook I can review the module at night or any time when I am free, but when it hangs up, then I can't do anything. Sometimes there is no electricity, due to load shedding, and whole day we cannot access moodle, so those days, I wish we had face to face classes only, and our learning did not depend on this tablet (FG2).

Students and faculty appreciated the assigned IT personnel from the blended team of the university, whose accessibility was almost like $24 / 7$ for faculty and students alike. Nonetheless, faculty suggested that an in house IT person should be ideal for handling technical crisis in campus. The university IT department provided the technological support and resources available, but certain issues related to the quality and limited functioning of NOOK, electricity, WIFI, university campus and hostel network and connectivity problems occurred that frustrated students and affected their adoption. As one student stated;

We have difficulty in opening the Moodle site from our hostel, problems like disconnection of the net again and again in hostel is there, and Nook does not have adequate soft-wares, so we cannot open or work on more than one window, and the powerpoint presentations are not downloading at times (FG1).

Since faculty had a desktop in their office, their concerns regarding nook were not much, but they had concerns regarding 
limited electronic resources available to them and students:

Students have to be called on campus just to watch the assessment CDs / movies available in our skills laboratory, as they are heavy files and cannot be uploaded on course site for students use. Even the existing course resources such as the Health assessments textbooks hard copies, simulated models or hard posters are not useful as they are not in digital e format. We need online resources such as online quizzes, podcast and skills vodcast and we need to either purchase them or develop professionally to maintain the quality (FG4).

Use of online resources required seeking of copyright from the publisher. Faculty verbalized that seeking copyright is a major task and challenging issue as they require support and guidance from the instructional designer and library personnel. The required resources need to be identified prior to the semester as otherwise the copyright is not received prior to uploading of each module. A faculty inquiring about the role of instructional designer stated;

The entire copy right issue is important because the infrastructure we have at this point don't support. We run a lot of delays in the modules putting up because we don't have copyright of certain resources. I don't think that faculty should be running around for copy right and this is something that should be done by a designated person... it should actually be instructional designer's or a librarian's task. I think that support for faculty is not there that leads to frustration (FG4).

Concerns about limited number of digital cameras to prepare vodcasts, single desktop in skills lab to upload the vodcast, were shared by students and faculty alike. Students were concerned that they cannot upload their vodcasts during lab timings due to technological limitations. A faculty explained;

We have 2 batches of 40 students, and we have 6 digital cameras at one time, sharing 6 cameras is not feasible for 40 student, they have limited time to practice the skill, make a assessment vodcast, edit it and upload it on a computer. In skills lab there is only one computer, so they have to go down to the self-access center and upload their vodcast. We do not allow cameras to be taken outside of lab, and that is another policy issue that we need to work upon, as there is risk of losing the cameras (FG4).

In terms of undertaking formal assessments for students, faculty shared that there are not enough desktops for taking online exam for 83 students, so they conducted online exam in two batches, as there were 40 desktops only. Faculty suggested investing in better handheld device for students so they could all synchronously sit for online test in a classroom.

\subsubsection{Category 5: Contextual Factors, Issues \& Challenges}

Participants shared certain contextual issues that influenced how they adopted to blended learning. These factors relevant to the educational ethos and socio cultural context included the diversity of students, academic demands and assessment complexities that affected their adoption to BL. Since this was the first skill based course to be transformed in the blended format, there were many concerns and fears in terms of $\mathrm{f}$ students' competence and mastery of skills. The major fear factor was the diversity among students in terms of their competency in spoken and written language. For many students, English was a second or third language, and they had difficulty expressing their thoughts and learning in clear, written language. Some students shared how they had to think twice and thrice before writing something, and needed to spend extra time on how to write their point clearly in forum. Besides different language skills, their internet and basic computer skills, typing and reading abilities also were very diverse and so affected their ease with BL.

Written communication becomes a record so I need to think twice and thrice before I write something on a forum. I speak different language and English is not good. My time used in thinking what to write and my typing slow so I take more time. I always slow in learning compared to peers (FG2).

Although all students were trained initially on how to access the course site and respond online in forums, a diverse level of participation was seen amongst them. Students who were married, had family or child care responsibilities or who worked part time, were pressed of time and usually participated less and during late evening hours when they had settled their chores in comparison to students who were young, single, or lived in hostel. Older students who had returned to school for higher studies after a long gap participated less as they were slow in reading, typing, managing computer and other resources. They were reserved and had difficulty in expressing their disagreements or questioning peers that was expected in forums. Some slow achiever students found it difficult to cope with the pace of modules and the dominant students overpowered them. Those students who did their nursing diploma training from the same university adopted fast, and participated more in discussion. As a student said;

When a module starts, there are lots of activities and readings to do and forum opens soon. They have done their RN diploma from here (university) so they are fast.... we face problem because we are not able to start studying... and finishing the first part and then we go to discussion forum, so like I am in second activity and they 
are in fourth activity. But if we study together we have ideas to discuss more and can take benefit of this discussion. And if we don't understand anything, we just copy paste information from book... and we not learn from it (FG3).

Students and faculty both verbalized that blended learning has improved their computer and IT skills, and made them internet savvy, however, some technical skills like making a vodcast were new and student needed more time from IT personnel, for which they felt difficulty during the semester. As one faculty voiced;

We wanted to use vodcast in the modules but we realized that students don't know how to make them, so we had to spend some time, apart from course hours, on teaching them how to make a vodcast. These could have been done in the orientation week before the semester starts so the students don't feel overwhelmed in learning these during course hours (FG4).

Students were aware that from this year the university has started to offer few courses as blended and they were concerned that it requires more work on their part. On average, a blended course required students to give 6-8 hours of learning time / week. Students viewed the assessments as overwhelming and competitive, since it included many tests and exams. Participants suggested reducing the number of assessments in the BL courses. A faculty relating to assessment voiced:

We overwhelm our students with too much assessment... we have to look at the number of assessments in a 3 credit course... like we have a quiz this week followed by a performance exam next week... I think as faculty we have to do soul searching and ask, do we really need that many assessments in a 3 credit course? (FG4).

\section{Discussion}

The findings of the study show that students felt motivated to participate in blended format. They found it easier to access the course material and activities anytime and anywhere. As per the intrinsic motivation theory, students tend to feel motivated in blended learning environment because of the autonomy that they have in terms of participation (Hartnett, 2009). Students also found faculty's responses as one of their motivational factors that urged them to perform better; Hartnett (2009) has shared the similar findings that came up in their study as well. However, the findings of the present study have highlighted some barriers to student motivation and readiness too. The students felt less confident on performance of skills independently, and they felt unsure of the content shared by their colleagues. Similar barriers have been shared by Song and Hill (2007) that decreased student motivation while performing in online courses.

In the current study, faculty shared that they were quite motivated to work in a blended format. It was quite expected as blended learning was a new approach for which faculty had been trained prior. However, some faculty shared issues such as increased time requirement, increased workload in preparation of the modules, and facilitating discussion forums. These findings concur with Tshabalala, Ndeya- Ndereya, and Merwe (2014) study, that was carried out in a developing rural university of South Africa, where faculty members felt time constrained and experienced increased workload in terms of preparation and implementation of web based activities. Moreover, in contrast to our study, in this study, faculty shared less confidence in terms of using blended learning strategies. This difference in findings is probably based on the fact that a well-structured faculty development program was offered for the faculty before the actual execution of BL strategies in health assessment course. Moreover, adequate support structures were also made available for the faculty, which were absent in the study by Tshabalala et al. (2014).

The study findings have also shown that students were very satisfied as they enjoyed learning using technological innovations and media. Similar findings have been reported by Connors et al. (2002), whereby students were found to be highly satisfied with the use of BL strategies in enhancing their nursing knowledge. Consistent findings were shared by Hsu (2011) who integrated BL strategies in a nursing ethics course for undergraduate students in Taiwan. The findings of this study report that the students were highly satisfied with the vodcasts of assessment skills that they developed and posted on course site. All the students in that group and the faculty provided feedback on the assessment skills demonstrated in the vodcast. The students found it full of learning as it provided them an opportunity to practice and then record. The vodcast and the feedback then remained available on Moodle for the rest of the semester to refer back at any point in time. Song and Hill (2007) support that students feel comfortable with blended learning as learning resources remain available online for a longer period of time, and can be referred to whenever required. Vodcasts of assessment skills i.e. virtual labs were a modified form of virtual reality (VR) that facilitates nursing students in developing competence in clinical skills through electronic simulation (Aebersold, Tschannen, \& Bathish, 2012; Honey, Diener, Connor, Veltman, \& Bodily, 2009; Kidd, Morgan, \& Savery, 2012; Lewis, 2009). However, this was the first time that we utilized this strategy in a skill based course, which was very well taken and appreciated by the students.

The study findings suggest that students appreciated the use of powerpoint and lecture, as well as skill performance vodcasts, and found them helpful for understanding the concepts. Schlairet (2010) and Pearce and Scutter (2010) reported similar findings for the use of podcasts in undergraduate nursing education. However, limitations with the use of podcasts 
reported in the literature are: issues in retrieving and downloading podcasts or vodcasts (Strickland et al.), and increased number of students not attending classes (Kardong-Edgren and Emerson, 2010). The former has been shared by the students in our study as well; whereas, the latter was not reported. In fact, it was found that listening to podcasts prior to the class, enriched class discussions.

In the current study, students shared that they found discussion forums very interactive. Moreover, students also shared their concerns in relation to the use of discussion forums, such as dominating students sharing increased number of posts quickly, overwhelming discussion forums as they are time consuming, perceived lack of faculty guidance during discussions. These findings are consistent with Blackmon (2012), who reported enhanced student interaction in discussion forums, and the issues of increased time requirement for participation, number of posts and students' participation being affected by the faculty's presence.

In terms of availability of resources, students shared issues in downloading e-resources due to connectivity issues and faculty indicated need for a permanent IT support person, which is consistent to Deltsidou, Gesouli-Voltyraki, Mastrogiannis, and Noula (2010) study findings, where limited access to internet connections was identified as a major problem. Fetter (2009) found obstacles to BL integration, such as IT skills and infrastructure insufficiencies, lack of support by administration, and lack of any IT integration standards by regulatory bodies. The issue of purchase of copy right material highlighted by the faculty in the current study was not found as such in the literature; this finding is quite context specific as the university just began with the blended learning; therefore there wasn't any repository of copyrighted material available. Rather, faculty had to search each time, the e-resources that can be used with copyrights.

The study also revealed the effect of some contextual factors which challenged participants in integration of BL strategies. The first contextual factor was the diversity of students that we had in class. As discussed in findings, those students who were well versed in English performed relatively better in discussion forums as compared to the ones whose first or second language wasn't English. Moreover, students were also quite diverse in terms of their ages, years of experience and in years lapsed between studies. This diversity affected their efficiency of employing IT skills and study skills. The young ones were better off at IT and study skills as compared to the older ones who had returned to the academic world after a long time. This difference in skills made them perform differently in online activities, which was very evident by their performance in discussion forums, hot potato quizzes etc. Kaur (2013) has also highlighted the challenge of ensuring that students can use IT skills successfully in blended courses. Another important finding that emerged was that students found activities and assessments in BL format quite overwhelming. Harnett (2009) found the similar findings. Since, students were taking multiple courses in BL format simultaneously, therefore, it was quite expected that they would find it overwhelming.

\section{Conclusion}

Faculty experienced numerous challenges while adopting to BL pedagogies. They felt that BL is an enriching experience for them and hoped that students' overall learning is enhanced due to increased engagement and interaction as compared to traditional format course. These findings can be the bases for planning, transforming and evaluating other blended courses to promote active engagement and critical thinking of students.

\section{References}

Aebersold, M., Tschannen, D., \& Bathish, M. (2012). Innovative simulation strategies in education. Nursing Research and Practice. http://dx.doi.org/10.1155/2012/765212

Blackmon, S. J. (2012). Outcomes of Chat and Discussion Board Use in Online Learning: A Research Synthesis. The Journal of Educators Online, 9 (2). http://www.thejeo.com/Archives/Volume9Number2/BlackmonPaper.pdf

Cassum, S. H. (2011). Perceptions and practices of critical thinking amongst faculty of nursing, medicine and education in Karachi. Pakistan. (Unpublished Master's Thesis), The Aga Khan University, School of Nursing and midwifery, Karachi, Pakistan.

Deltsidou, A., Gesouli-Voltyraki, E., Mastrogiannis, D., \& Noula, M. (2010). Undergraduate nursing students' computer skills assessment: A study in Greece. Health Science Journal, 4(3), 182-188.

Farrell, M. J., \& Rose, L. (2008). Use of mobile handheld computers in clinical nursing education. Journal of Nursing Education, 47(1), 13-19. http://dx.doi.org/10.3928/01484834-20080101-03

Fetter, M. S. (2009). Baccalaureate nursing students' information technology competence: Agency perspectives. Journal of Professional Nursing, 25(1), 42-49. http://dx.doi.org/10.1016/j.profnurs.2007.12.005

Gagne, J. C., Bisanar, W. A., Makowski, J. T., \& Neumann, J. L. (2012). Integrating informatics into the BScN curriculum: A review of the literature. Nurse Education Today, 32, 675-682. http://dx.doi.org/10.1016/j.nedt.2011.09.003

Garrett, B., \& Jackson, C. (2006). Mobile clinical learning using wireless personal digital assistants for professional 
healthcare students. International Journal of Learning, 13 (4), 135-143.

Gormley, G. J., Collins, K., Boohan, M., Bickle, I. C., \& Stevenson, M. (2009). Is there a place for e -learning in clinical skills? A survey of undergraduate medical students' experiences and attitudes. Medical Teacher, 31(e6-e12). http://dx.doi.org/10.1080/01421590802334317

Hartnett, M. (2009). Factors undermining motivation in place-based blended learning. In Same places, different spaces. Proceedings ascilite Auckland 2009, 439-443. http://www.ascilite.org.au/conferences/auckland09/procs/hartnett.pdf

Holloway, I., \& Wheeler, S. (2002). Qualitative Research in Nursing. (2 $2^{\text {nd }}$ ed.). UK; Blackwell Science.

Honey, M. L., Diener, S., Connor, K., Veltman, M., \& Bodily, D. (2009). Teaching in virtual space: Second life simulation for haemorrhage management. Proceedings Ascilite Auckland, 1222-1224.

Hsu, L. (2011). Blended learning in ethics education: A survey of nursing students. Nursing Ethics, 18(3), 418-430. http://dx.doi.org/10.1177/0969733011398097

Kardong-Edgren, S., \& Emerson, R. (2010). Student adoption and perception of lecture podcasts in undergraduate bachelor of science in nursing courses. Journal of Nursing Education, 49(7), 398-401. http://dx.doi.org/10.3928/01484834-20100224-04

Kidd, L. I., Morgan, K. I., \& Savery, J. R. (2012). Development of a mental health nursing simulation: Challenges and solutions. Journal of Interactive Online Learning, 11(2), 80-89.

Koeniger-Donohue, R. (2008). Handheld computers in nursing education: A PDA pilot project. Journal of Nursing Education, 49(2), 74-77. http://dx.doi.org/10.3928/01484834-20080201-01

Lewis, R. A. (2009). The effect of virtual clinical gaming simulations on student learning outcomes in medical-surgical nursing education courses. Unpublished Thesis. Retrieved from http://mds.marshall.edu/etd

McDowell, D. E., \& Ma, X. (2007). Computer literacy in baccalaureate nursing students during the last 8 years. CIN: Computers, Informatics, Nursing, 25(1), 30-36. http://dx.doi.org/10.1097/00024665-200701000-00010

McNiff, J., \& Whitehead, J. (2000). Action Research in Organisations. USA: Routledge. http://site.ebrary.com/lib/agakhan/Doc?id=5002100

Pearce, K., \& Scutter, S. (2010). Podcasting of health sciences lectures: Benefits for students from a non-English speaking background. Australian Journal of Educational Technology, 26(7), 1028-1041.

Schlairet, M. C. (2010). Efficacy of podcasting: Use in undergraduate and graduate programs in a college of nursing. Journal of Nursing Education, 49(9), 529-533. http://dx.doi.org/10.3928/01484834-20100524-08

Skiba, D. J., Connors, H. R., \& Jeffries, P. R. (2008). Information technologies and the transformation of nursing education. Nursing Outlook, 56, 225-230. http://dx.doi.org/10.1016/j.outlook.2008.06.012

Song, L., \& Hill, J. R. (2007) A Conceptual Model for Understanding Self-Directed Learning in Online Environments. Journal of Interactive Online Learning, 6(1), 27-42. www.ncolr.org/jiol

Strickland, K., Gray, C., \& Hill, G. (2012). The use of podcasts to enhance research-teaching linkages in undergraduate nursing students. Nurse Education in Practice, 12(4), 210-214. http://dx.doi.org/10.1016/j.nepr.2012.01.006

Tshabalala, M., Ndeya-Ndereya, C., \& Merwe, T. V. (2014). Implementing Blended Learning at a Developing University: Obstacles in the way. The Electronic Journal of e-Learning, 12(1), 101-110. Retrieved from www.ejel.org

This work is licensed under a Creative Commons Attribution 3.0 License. 